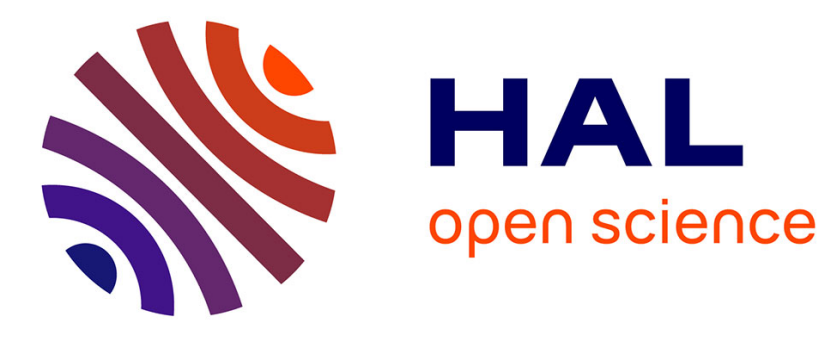

\title{
Fixism and conservation science
}

Alexandre Robert, Colin Fontaine, Simon Veron, Anne-Christine Monnet, Marine Legrand, Joanne Clavel, Stéphane Chantepie, Denis Couvet, Frédéric Ducarme, Benoît Fontaine, et al.

\section{- To cite this version:}

Alexandre Robert, Colin Fontaine, Simon Veron, Anne-Christine Monnet, Marine Legrand, et al.. Fixism and conservation science. Conservation Biology, 2017, 31 (4), pp.781-788. 10.1111/cobi.12876 . hal-01480250

\section{HAL Id: hal-01480250 https://hal.sorbonne-universite.fr/hal-01480250}

Submitted on 1 Mar 2017

HAL is a multi-disciplinary open access archive for the deposit and dissemination of scientific research documents, whether they are published or not. The documents may come from teaching and research institutions in France or abroad, or from public or private research centers.
L'archive ouverte pluridisciplinaire HAL, est destinée au dépôt et à la diffusion de documents scientifiques de niveau recherche, publiés ou non, émanant des établissements d'enseignement et de recherche français ou étrangers, des laboratoires publics ou privés. 


\section{Fixism and conservation science}

Alexandre Robert ${ }^{1 *}$, Colin Fontaine ${ }^{1}$, Simon Veron ${ }^{1}$, Anne-Christine Monnet $^{1}$, Marine Legrand $^{1}$, Joanne Clavel ${ }^{1}$, Stéphane Chantepie ${ }^{1}$, Denis Couvet ${ }^{1}$, Frédéric Ducarme ${ }^{1}$, Benoît Fontaine $^{1}$, Frédéric Jiguet ${ }^{1}$, Isabelle le Viol ${ }^{1}$, Jonathan Rolland ${ }^{1}$, François Sarrazin ${ }^{1}$, Céline Teplitsky $^{1,2} \&$ Maud Mouchet ${ }^{1}$

${ }^{1}$ Centre d'Ecologie et des Sciences de la Conservation (CESCO UMR7204), Sorbonne Universités, MNHN, CNRS, UPMC, CP135, 43 rue Buffon, 75005, Paris, France.

${ }^{2}$ Centre d'Ecologie Fonctionnelle et Evolutive UMR 5175, Campus CNRS, 1919 Route de Mende, 34293 Montpellier, cedex 5, France

* email arobert@mnhn.fr

Keywords: ethics, biodiversity, species, evolutionary potential, Anthropocene Running head: Fixism and conservation 


\begin{abstract}
The field of biodiversity conservation has recently been criticized as relying on a fixist view of the living world, in which existing species constitute at the same time the targets of conservation efforts and static states of reference, which is in apparent disagreement with evolutionary dynamics. We review the prominent role of species as conservation units and we provide justifications to the species approach, in relation with the discrepancy between the time scales of macroevolution and human influence. We also show that conservation science addresses many other levels of biological integration. We then discuss the common "benchmark" approach, aiming at using past biodiversity as a reference to conserve current biodiversity. We demonstrate the necessity of biodiversity benchmarks and we show that they are based on reference processes rather than fixed reference states. Overall, we argue that the ethical and theoretical frameworks underlying conservation research are based on macroevolutionary processes. Current species, phylogenetic, community, and functional conservation approaches constitute short-term responses to short-term human effects on these reference processes, and these approaches are consistent with evolutionary principles.
\end{abstract}




\section{Introduction}

Modern biology is anchored in evolutionary principles according to which speciation, extinction, and character evolution shape the patterns of biological diversity (hereafter biodiversity) and their changes through time. Evolutionism opposes fixism, the idea that species do not change, recently defined as "the doctrine that the most important properties of the members of any species, those properties allowing for their classification as members of this species, cannot vary beyond definite limits" (Barberousse \& Samadi 2010).

Although fixism is considered by most biologists an obsolete theory (Dobzhansky 1973), recent publications suggest that a growing sector of conservation science partly relies on a fixist view of the living world. Most critics do not claim that conservation scientists themselves are fixist, but they denounce a pattern-oriented view of biodiversity conservation based primarily on the study and management of species as static typological units. Although most biologists recognize that individual variation is ubiquitous in nature and is the basis for evolutionary change, typological thinking is still pervasive (Ashley et al. 2003). Such a typological approach is associated with the mistaken view that species are relatively fixed, independent entities (Ashley et al. 2003; Diniz-Filho et al. 2013) rather than interacting evolutionary units (Rojas 1992) and that their diversity and distributions are static biological phenomena (Winker 1996). This static conservation paradigm (Hannah et al. 2002) has been the subject of much criticism (Ibisch et al. 2005; Toledo et al. 2012; Harmsen \& Foster 2014; Harris et al. 2015). The apparent difficulty of framing policies to preserve dynamic processes rather than objects (threatened biodiversity) implies that most conservation strategies are inconsistent with an evolutionary perspective (Smith et al. 1993; Mace \& Purvis 2008; Grant et al. 2010). Associated with these criticisms is the view that conservation efforts to save some threatened species are grounded in the past (Ibisch et al. 2005), reductionist, artificial, and scientifically inconsistent (Kareiva \& Marvier 2012). Finally, it has been argued that 
evolutionary biology has little impact on practical conservation because of the limited participation of evolutionary biologists in conservation science and the ignorance (or neglect) of evolutionary processes by managers. Thus, for over 20 years, biologists have repeatedly claimed that conservation needs to put more emphasis on evolution(e.g., Smith et al. 1993, Hannah et al. 2002; Stockwell et al. 2003; Mace \& Purvis 2008; Hendry et al. 2010; Carroll et al. 2014).

Conservation science is interdisciplinary and draws on natural and social sciences to protect biodiversity components and processes from deleterious anthropogenic activities and to build mutually beneficial relationships between humans and biodiversity. An evolutionary conservation perspective has existed for several decades. In 1985 Soulé stated that evolution is not only the one and only framework with which to describe and understand biological processes but also one of the primary ethical postulates for conservation. Along with the acknowledgment that the drivers of the current biodiversity crisis are likely to disrupt some evolutionary processes (Palumbi 2001; Hendry et al. 2010), conservation science has provided concepts and tools based on evolutionary knowledge. For instance, conservation genetics (Frankham et al. 2003) addresses genetic deterioration in wild and captive populations, future evolutionary potential, and the designation of evolutionarily significant units, which has direct consequences for planning and management in a diversity of conservation approaches, from translocations to protected areas.

We reviewed the main criticisms of conservation science regarding its presumed fixist component and attempt to demonstrate that most practices of conservation incorporate the contemporary understanding of dynamic ecological and evolutionary processes and that the evolutionary-based postulates constructed over 30 years ago provide a way to solve most apparent contradictions between biodiversity conservation and evolution. 
We considered the most recurrent criticism of conservation science: most methods used to protect biodiversity are intended to save species from extinction, which apparently contradicts our knowledge of evolutionary processes. We also addressed the problem of the shifting frame of reference when seeking to conserve an evolving biodiversity in dynamic environments and human societies and under changing perceptions. Finally, we examined how evolutionarily driven goals of conservation are affected by the ultimate motivations underlying these goals. Consideration of these 3 topics together allowed us to emphasize important distinctions among general conservation goals, the ultimate motivations underlying these goals, and the practices used to achieve them. We suggest, in particular, that fixist methods are sometimes used to serve evolutionarily sound conservation goals and vice versa.

\section{Saving species, genes, or functions}

The species problem

The species has long been the basic unit in conservation biology, notably in the process of defining conservation status (e.g., IUCN 2014). Classifications of threatened species are directly connected to legislation in many countries and often considered in triage discussions and in defining protected areas based on the idea that species-rich areas or those with threatened species should be prioritised. Other types of conservation actions, such as translocations or forms of legal protection, are directly implemented for particular species, and academic research in conservation biology is often focused on the species level (Fazey et al. 2005).

Two lines of arguments feed the criticisms of the species approach in conservation science. The first is related to the complexity, limits, and artificiality of the species definition, which has been one of the most controversial topics in biology for over 150 years. The complexity of the species definition is linked to the multiplicity of the approaches to species 
identification (i.e., the species concepts) (Hey 2006). Although the criteria inherent to species concepts are assumed to reflect the divergence of evolutionary lineages (de Queiroz 2007), the relevance of species as important functional or evolutionary units has been questioned (Winter et al. 2013), and there is still much debate about species recognition and nomenclatural rules for most biodiversity (viruses, archaea, bacteria, fungi, etc.). Thus, some authors consider the use of species in conservation science is partly unjustified (Rojas 1992). The second line of argument is related to the apparent contradiction between species conservation and evolutionary dynamics (Grant et al. 2010). First, species evolve continuously, and species extinction is part of the evolutionary process, but conserving species implies incorrectly treating them as fixed entities. Second, counter-arguments on the irreversibility of species extinction to justify their conservation (e.g., Hunter et al. 2014) are fixist arguments that ignore intraspecific genetic variation and the fact that irreversible loss of genetic variation is part of the evolutionary process (e.g., from an evolutionary perspective, the death of 1 individual is also an irreversible phenomenon).

This general dispraise is amplified because both scientific interest and public support for conservation efforts focus on certain species, such as large, charismatic vertebrates (Fazey et al. 2005). Kareiva and Marvier (2012) describe concern for local charismatic species threatened with extinction as "nostalgia" for "the world as it once was" and suggest that conservation efforts are wrongly directed to biodiversity units that are no longer adapted to the current environment.

\section{Evolutionary versus human time scale and justifications for the species approach}

Consistent with some seminal conservation biology publications (Frankel 1974; Soulé 1985), many biologists agree that maintaining evolutionary potential and processes is a primary concern of conservation science (e.g., Crandall et al. 2000; Stockwell et al. 2003; Hendry et 
al. 2010). However, assuming that conservation biology should ultimately seek to restore the evolutionary balance of speciation and extinction events rather than save particular species, saving species remains one pragmatic response of conservationists to the biodiversity crisis for several reasons. First, there is a strong discrepancy between the time scale of macroevolutionary processes (e.g., extinction or speciation) and the time scale of human influence. The current species extinction rate is much higher than background extinction rates (Barnosky et al. 2011), and the anthropogenic causes of most extinction events are widely acknowledged (Brook et al. 2008). The period of strong human influence is very short relative to the average longevity of species (a few hundred years versus 1 million years or more) (Jenkins 1992; Hunters 1996; Brook et al. 2008). Thus, most species threatened by human activities would not become extinct during the human time scale in the absence of these activities and species will experience human influence during only a small portion of their existence, a period during which there would be little opportunity to adapt to environmental change. For comparison, some previous mass extinction events, such as the Cenomanian-Turonian crisis that lasted 500,000 years, may have generated adaptive responses in the affected populations (Erwin 1998). Saving particular species from humaninduced extinction is a way to reduce the global rate of untimely extinctions (Soulé 1985) and thus minimise humanity's effect on evolutionary trajectories via both direct extinction effects of the target species at the phylogenetic level (i.e., at the level of the evolutionary history) and secondary effects mediated by community processes and coevolution (Lawrence et al. 2012). Therefore, saving a species is both a fixist goal in itself in the short term and a relevant means to achieve evolutionarily sound goals in the longer term.

Second, human pressure and feedback (e.g., in response to exploitation) act at the population or species scale, and the population is the level at which scientists are able to make reliable and sound predictions about persistence that can be reasonably extended to the scale of the 
entire species. Thus, threatened-species listing constitutes a valuable way to better characterise the extinction risk at the phylogenetic level, for example. Further, key microevolutionary processes, such as genetic deterioration and adaptation to global changes (Hendry et al. 2010), have been historically described and theorised at the population, metapopulation, and species levels, and numerous evolutionary biologists and phylogenetic systematists consider that, at least for vertebrates, species are important evolutionary units (Cracraft 1989).

Finally, although some higher taxa (e.g., insects, mollusks, and fungi) are clearly neglected in biodiversity conservation policies and research, the focus on large charismatic species has been justified by functional and pragmatic arguments. For example, among groups of vertebrates, large species are particularly vulnerable to extinction (Fritz \& Purvis 2010) and have large impacts on communities and ecosystems (Ripple et al. 2014). Such flagship species can also be used to leverage strong support because species are, in the realm of human perception, the most immediate and direct way to perceive and apprehend an element of biodiversity.

\section{Conservation phylogenetics, communities, and functions}

The species is one conservation unit among others, and modern conservation science embraces both intraspecies and multispecies approaches to address biodiversity loss. Since the 1990s, scientists have proposed a phylogenetic approach to conservation to prioritise protecting evolutionarily distinct groups or areas that encompass the richness of the tree of life (Faith 1992). Projections of biodiversity loss show a loss of phylogenetic diversity for many groups that is higher than expected according to a model of random extinctions (Jono \& Pavoine 2012). 
Conservation biology has also begun to embrace community-level approaches, which has been fuelled by the development of network ecology, in which the dependencies among species within communities are explicitly considered. Such approaches allow for the identification of ecological interactions among species to determine the response of target species to perturbations or conservation strategies and have begun to stimulate approaches that focus on entire ecological communities, including the patterns of interaction among species (Forup et al. 2008), rather than target species.

In addition to the species, phylogenetic, and community approaches, the biodiversityecosystem functioning framework offers another alternative to species-centred approaches to explicitly link species to ecological processes and fluxes. This framework relies on the observation that one species can perform more than one ecological function; species are not ecologically equivalent; and species can be functionally redundant. Functional ecologists have defined the taxon-free concept of functional types (i.e., groups of species having similar ecological effects) or, more recently, functional entities (i.e., unique combinations of functional traits [Mouillot et al. 2014]).

Recently, attempts have been made to integrate these approaches by introducing the use of phylogenetic relatedness to understand the ecological and evolutionary processes underlying community assembly (Pavoine \& Bonsall 2011) under the assumption that phylogenetic signal can be informative regarding functional diversity, ecosystem functioning (Faith 2013, but see Winter et al. 2013), and the similarity of the ecological roles of species (Webb et al. 2002). Although practical applications of the phylogenetic, community, and functional frameworks are still rare, these approaches have recently moved from pure theory to early stages of implementation (e.g., Isaac et al. 2007; Laity et al. 2015). 


\section{Reference states and processes}

\section{The benchmark problem}

Using reference states to compare current biodiversity with past biodiversity is a common practice in conservation biology. Reference states, or benchmarks, can be either natural or human modified (Willis \& Birks 2006), and time references as diverse as prehumans, preagriculture, the year 1500, and the year 1970 have been used in conservation studies. Conservation approaches as diverse as establishing protected areas, restoring past systems, and ex situ conservation rely on this benchmark approach in which reference states are used to define conservation goals. Three major conceptual problems and criticisms have been raised considering these approaches. The first basic problem with the benchmark approach is that the preservation of pristine, prehuman landscapes is impossible if such landscapes no longer exist. The term Anthropocene refers to a model in which humans have changed Earth's surface systems sufficiently to affect the biosphere on a scale comparable with some past geologic epochs or periods. If human-induced changes in land cover, biogeochemical cycling, and climate are global (Corlett 2015), establishing undisturbed protected areas is impossible and useless (Thomas 2011).

The second problem is that biodiversity benchmarks are necessarily arbitrary. Ecosystems evolve continuously, implying that they have no original state to be considered as a reference (Toledo et al. 2012); any arbitrary reference state is affected by the human perception of the environment, which changes over human generations (Pauly 1995); and valuing a particular system at a particular time is nontrivial if the system changes continuously (Hale et al. 2014). This problem is particularly acute in the context of species or ecosystem restoration. Seddon et al. (2014) note, for example, that the term rewilding has been widely and variously misused, with meanings ranging from the reintroduction of any recently extirpated species to the proposed introduction of megafauna to replace species lost 13,000 years ago (Pleistocene 
rewilding). This semantic discrepancy reflects the heterogeneity of the systems, states, and times of reference used in restoration ecology and echoes the conceptual difficulty of assessing what is wild or natural (Willis \& Birks 2006).

The third and most important criticism of the benchmark approach is that it is used to achieve and maintain patterns (a predefined optimum) rather than processes (Harmsen \& Foster 2014) and ignores evolutionary and environmental dynamics (Thomas 2011; Toledo et al. 2012). For example, ex situ conservation techniques aimed at protecting endangered species outside their natural habitat, in captive animal populations, botanic gardens, seed banks, or cryogenic zoos, raise the concern of freezing evolutionary processes. Such approaches focus on some fixed evolutionary patrimony but do not allow for the conservation of evolutionary processes. Similar concerns have been raised to criticise more interventionist actions aimed at restoring past systems, such as Pleistocene rewilding and deep deextinction. Deep deextinction aims to use synthetic biology to revive long-extinct species, such as the woolly mammoth or the dodo (Seddon et al. 2014), and to reestablish them in natural environments. The expected evolutionary benefit of deextinction is low (Robert et al. 2016), and some authors consider it an unnatural and hubristic reversal of natural selection (Sandler 2013). Most of these criticisms are also directed toward the Pleistocene rewilding approach, which has been qualified as ignorant of landscape and human dynamics, species interactions, and coevolution (Toledo et al. 2012).

\section{Necessity of the benchmark approach}

The benchmark approach remains an important component of the scientific method; neutral models, null hypotheses, starting points, and control groups are necessary references to assess, understand, and quantify effects and correlations. In biodiversity conservation, benchmarks are necessary to quantify biodiversity with a different perspective than 
conservation actions themselves, and it is an equally essential prerequisite to legitimate actions with facts rather than concepts alone. Most of the criticisms raised do not disagree with the benchmark approach per se; rather, they are aimed at its primary application to fixed patterns rather than processes. If one considers conservation actions from a broad perspective by considering proximal practices within their larger goals, some criticisms vanish.

As discussed above, conservation biology is not a response to the extinction of particular species; rather, it seeks to address the extinction process affecting biodiversity at the global scale and to analyze this pattern within long-term evolutionary dynamics. Although subject to uncertainty and highly debated (Costello et al. 2013), the global rate of species extinction is one of the most emblematic diagnoses made by conservation scientists, and this rate is always compared with its benchmarks (e.g., global extinction rates during times of normal background extinction; previous, non-human mass extinctions; and even extinction dynamics within particular clades) (Quental \& Marshall 2010). Similarly, current patterns of extinction selectivity in the phylogeny (i.e., the relative vulnerability of taxa to extinction) are compared with "basal" selectivity (Barnosky et al. 2011). Here, benchmarks used by conservationists are not based on reference states but on reference macroevolutionary processes, such as extinction dynamics. Thus, the reference to natural or prehuman patterns and processes is essential not only to justify biodiversity conservation as a whole (such as natural and human-induced climate variability require disentanglement in the climatewarming debate) but also to implement evolutionarily meaningful actions (Willis \& Birks 2006).

The study of climate change has profoundly influenced conservation science since the early 2000s had has led to a shift from a preservationist philosophy to a more anticipatory model of action (Minteer \& Collins 2012), which relies on processes (such as range shift or adaptation) rather than fixed reference states and on establishing new connections between 
conservationists and evolutionary biologists (Hendry et al. 2010). The developing theory of adaptation to climate change (e.g., Chevin et al. 2010) is anchored in the general framework of the human, environmental, ecological, and evolutionary scenarios of the future. This dynamic and future-oriented view of biodiversity does not contradict past and current conservation practices, such as reserve establishment, restoration, and ex situ approaches. Although no one reasonably denies that humans have affected the entire planet (Thomas 2011), many conservationists agree that establishing reserves remains one of the best and most efficient tools to slow biodiversity loss (Hunter et al. 2014), and recent results suggest that protected areas can mitigate climate-change impacts on biological communities (Gaüzère et al. 2016). The design and management of protected areas now address processes such as ecological interactions and adaptation (Lawson 2013). Outside these protected areas, it has been suggested that evolutionary dynamics in human landscapes ought to be accepted (Sarrazin \& Lecomte 2016) in order to reduce anthropogenic directional selective pressures on biodiversity. This implies, in particular, that the dynamics of the ordinary biodiversity (e.g., common birds or pollinator insects that are not listed as threatened but may be rapidly declining and may have already accumulated climatic debts) should be considered. Similarly, ex situ conservation is not an end in itself ; rather, it aims to establish "dynamic reserves of evolutionary potential" (Stockwell et al. 2003) to create or restore populations or ecosystems in the wild (Robert 2009). Minimisation of the loss of genetic variation, selection relaxation, and adaptation to captivity are addressed via the management of the size and connectivity of captive populations and the implementation of gene flow from wild to captive populations. Finally, most ecological restoration approaches are not intended to return to some arbitrary historical state but rather promote adaptation (Aitken \& Whitlock 2013). 


\section{Conservation values and evolution}

\section{Evolutionary trajectories}

The general objective of conserving evolutionary processes (Crandall et al. 2000) can be translated into concrete conservation practices at relatively short-term (e.g., decades or centuries) and small phylogenetic scales (e.g., at the species level) because such objectives can be related to the potential for, for example, a given species to avoid extinction by responding evolutionarily to environmental changes and because existing genetic variation is the primary fuel for contemporary evolution (Hendry et al. 2010). However, at the global macroevolutionary scale, the maintenance of evolutionary processes becomes tautological because there is no alternative to evolution. Species extinctions and even mass extinctions are parts of the evolutionary processes that shape biodiversity (Erwin 1998). One corollary is that conservation scientists must necessarily make choices about the evolutionary processes and trajectories that they intend to favor for the future. These choices depend on the ultimate motivation to conserve biodiversity.

Historical conservation biology (hereafter classical conservation) relies on biocentric ethical postulates related to the intrinsic value of species (Vucetich et al. 2015), according to which species have a right to continued existence (Doak et al. 2013). Over the last 30 years, more utilitarian and anthropocentric arguments have enriched the values of conservation science (Mace 2014). These values rely on the collective benefits of biodiversity functions to humans, known as ecosystem services. The science of ecosystem services has benefited from ecological research on the role of biodiversity in ecosystem properties and functions (Cardinale et al. 2012) and is anchored in the new ecology (Schmitz 2016) and Anthropocene (Lövbrand et al. 2015) research fields. These fields focus on the interdependencies between humans and the natural world, emphasizing the importance of conserving species diversity because it offers a portfolio of options to keep global socioecological systems resilient in the 
face of environmental change. The Anthropocene research also raises important challenges in the fields of the humanities and social sciences by questioning the reflexivity of the power of humans to shape the environment, the separation of humans and nature (Tidball 2012), and the social consequences of the dominance of humans on the planet (Palsson et al. 2013). Along with the rise of these new motivations and research questions, the multidisciplinary field of conservation science has progressively replaced conservation biology through the integration of nonbiological disciplines in conservation research, such as climate sciences, public policy, economics, sociology, and psychology.

The various and complementary points of view on biodiversity conservation have begun to confront each other (Tallis \& Lubchenco 2014) through debate about the "new conservation", which advocates a primarily human-centred conservation ethic focused on human development (Kareiva \& Marvier 2012) and economic growth (Nordhaus \& Shellenberger 2007). Advocates of the new conservation argue that some classical conservation practices rely on fixism, asserting for example that these practices are anachronistic and scientifically unsupportable (Doak et al. 2013). Whereas much of the opposition between these two conservation movements relies on an ideological component as well as on mutual misunderstanding and caricature (Hunter et al. 2014), their implementation would favour distinct evolutionary processes and biodiversity trajectories. From an evolutionary perspective, the ultimate aim of most classical conservation advocates is to minimise the evolutionary footprint of humans on biodiversity by reducing human pressure on the environment, stopping rapid population and species extinctions, and promoting autonomous biodiversity responses to environmental changes. Such goals will necessarily generate different evolutionary trajectories (Sarrazin \& Lecomte 2016) relative to the new conservation's moving target of providing ecosystem services to a fast-growing population whose requirements change through time. 


\section{Human-biodiversity trade-off}

An important point raised by the two opposing movements is the role of the relationship between biodiversity conservation and human well-being. Partisans of the new conservation indicate the existence of trade-offs between conservation actions and human well-being, development, and economic growth (Kareiva \& Marvier 2012; Nordhaus \& Shellenberger 2007). Classical conservationists use a rhetoric of resource sharing between humans and other species, which is consistent with these trade-off arguments, and some advocate reducing human numbers and economic growth (Noss et al. 2013).

The supposed trade-off between humans and biodiversity conservation implicitly fuels the arguments regarding the fixist component of classical conservation, which prioritises species that are no longer adapted to the Anthropocene over human development. New conservationists indicate the artificiality of some classical conservation practices (Kareiva \& Marvier 2012) that are considered an expression of human values (Sarkar 2012). However, these criticisms are incorrectly based on a rhetoric of the naturalization of human development via the market economy, yet such development is related to political and societal choices (Picketti 2014) that are no less expressions of human values than the biocentric ethic of classical conservation. Most authors agree that human well-being generally benefits from biodiversity conservation and that human development is more complex than economic growth alone; it depends heavily on the ability to manage finite energetic resources available on Earth, avoid catastrophic human extinction, and mitigate the deleterious effects of human demographics and economic growth. Thus, some authors advocate limiting human demands on the biosphere for both biocentric and anthropocentric reasons (Noss et al. 2013). 


\section{Conclusions}

The functional and normative postulates constructed over 30 years ago (Soulé 1985) provide a way to solve many apparent contradictions between biodiversity conservation and evolution because conservation efforts are not directed toward fixed patterns or products but are, rather, directed toward evolutionary processes; scientists do not need fixed reference states to conserve biodiversity because they already use evolutionary processes as references; these references are intimately linked to knowledge of the components, mechanisms, and history of life since its origin, which implies that short-term human history falls outside evolution. Although such an approach to conservation is based on an ethic primarily centred on the intrinsic value of biodiversity, the rise of more anthropocentric perspectives has broadened its interdisciplinary component and has attracted more interest and support from society. The important debate between the classical and new conservation movements not only questions humanity's relationship with biodiversity and its evolution but also emphasizes the political foundations and implications of all conservation practices. One important issue is to ensure that the ideological and political components of this opposition do not weaken the voices of conservation scientists or distract them from their original goals. In particular, we must accept that conservation science relies on human values and that this does not make it a fixist discipline.

\section{Acknowledgments}

C.T. and S.C. were funded by the French Agence Nationale de la Recherche (grant ANR-12ADAP-0006). We thank E. Porcher, G. Lois, M. Jeanmougin, R. Julliard, A.-C. Prévot, A.C. Torres, L. Mermet, and two anonymous reviewers for helpful comments. 


\section{Literature cited}

Aitken SN, Whitlock MC. 2013. Assisted gene flow to facilitate local adaptation to climate change. Annual Reviews of Ecology, Evolution and Systematics 44:13.1-13.22.

Ashley MV, Wilson MF, Pergams ORW, O'Dowd DJ, Gende SM, Brown JS 2003. Evolutionary enlightened management. Biological Conservation 111:115-123.

Barberousse A, Samadi S. 2010. Species from Darwin onward. Integrative Zoololy 5:187197.

Barnosky AD et al. 2011. Has the Earth's sixth mass extinction already arrived? Nature 471:51-57.

Brook BW, Sodhi NS, Bradshaw CJA. 2008. Synergies among extinction drivers under global change. Trends in Ecology and Evolution 23:453-460.

Cardinale BJ et al. 2012. Biodiversity loss and its impact on humanity. Nature 486:59-67.

Carroll SP, Jørgensen PS, Kinnison MT, Bergstrom CT, Denison RF, Gluckman P, Smith TB, Strauss SY, Tabashnik BE 2014. Applying evolutionary biology to address global challenges. Science 346:313-346.

Chevin LM, Lande R, Mace GM. 2010. Adaptation, plasticity, and extinction in a changing environment: towards a predictive theory. PLoS Biology 8 (e1000357)

Corlett RT. 2015. The Anthropocene concept in ecology and conservation. Trends in Ecology \& Evolution 30:36-41.

Costello MJ, May RM, Stork NE. 2013. Can we name Earth's species before they go extinct. Science 339:413-415.

Cracraft J. 1989. Speciation and its ontology: the empirical consequences of alternative species concepts for understanding patterns and processes of differentiation. Pages 28-59 in Otte D, Endler JA, editors. Speciation and its consequences. Sinauer Associates, Inc, Sunderland. 
Crandall KA, Bininda-Edmonds ORP, Mace GM, Wayne RK. 2000. Considering evolutionary processes in conservation biology. Trends in Ecology and Evolution 15:290-295.

De Queiroz K. 2007. Species concepts and species delimitation. Systematic Biology 56:879_ 886.

Diniz-Filho JA, Loyola RD, Raia P, Mooers AO, Bini LM. 2013. Darwinian shortfalls in biodiversity conservation. Trends in Ecology \& Evolution 28:689-695.

Doak DF, Bakker VJ, Goldstein BE, Hale B 2013. What is the future of Conservation? Trends in Ecology and Evolution 29:1-5.

Dobzhansky T. 1973. Nothing in Biology Makes Sense Except in the Light of Evolution. The American Biology Teacher 35:125-129.

Erwin DH. 1998. The end and the beginning: recoveries from mass extinctions. Trends in Ecology and Evolution 13:344-349.

Faith DP. 1992. Conservation evaluation and phylogenetic diversity. Biological Conservation 61:1-10.

Faith DP. 2013. Biodiversity and evolutionary history: useful extensions of the phylogenetic diversity assessment framework. Annals of the New York Academy of Sciences 1289:69-89.

Fazey I, Fischer J, Lindenmayer DB. 2005. What do conservation biologists publish? Biological Conservation 124:63-73.

Forup ML, Henson KE, Craze PG, Memmott J. 2008. The restoration of ecological interactions: plant-pollinator networks on ancient and restored heathlands. Journal of Applied Ecology 45:742-752.

Frankel OH. 1974. Genetic conservation - our evolutionary responsibility. Genetics 78:5365. 
Frankham R, Ballou JD, Briscoe DA. 2003. Introduction to Conservation Genetics. $3^{\text {rd }}$ edition. Cambridge University Press, Cambridge.

Fritz SA, Purvis A. 2010. Phylogenetic diversity does not capture body size variation at risk in the world's mammals. Proceedings of the Royal Society of London B 277:24352441.

Gaüzère P, Jiguet F, Devictor V. 2016. Can protected areas mitigate the impacts of climate change on bird's species and communities? Diversity and Distribution 22:625-637.

Grant F, Mergeay J, Santamaria L, Young J, Watt AD. 2010. Evolution and Biodiversity: The evolutionary basis of biodiversity and its potential for adaptation to global change. Report of an e-conference.

Hale B, Lee A, Hermans A. 2014. Clowning around with conservation: Adaptation, reparation, and the new substitution problem. Environmental Values 23:181-198.

Hannah L, Midgley G, Lovejoy T, Bond WJ, Bush M, Lovett JC, Scott D, Woodward FI. 2002. Conservation of biodiversity in a changing climate. Conservation Biology 16:264-268.

Harmsen BJ, Foster RJ. 2014. What Are We Trying to Conserve? BioScience 64:170.

Harris RMB, Carter O, Gilfedder L, Porfirio LL, Lee G, Bindoff NL. 2015. Noah's Ark Conservation Will Not Preserve Threatened Ecological Communities under Climate Change. PLoS ONE 10:e0124014.

Hendry AP et al. 2010. Evolutionary biology in biodiversity science, conservation, and policy: a call to action. Evolution 64:1517-1528.

Hey J. 2006. On the failure of modern species concepts Trends in Ecology and Evolution 21:447-450.

Hunter ML, Redford KH, Lindenmayer DB. 2014. The complementary niches of anthropocentric and biocentric conservationists. Conservation Biology 28:641-645. 
Hunter ML. 1996. Benchmarks for managing ecosystems: Are human activities natural? Conservation Biology 10:695-697.

Ibisch PL, Jennings MD, Kreft S. 2005. Biodiversity needs the help of global change managers, not museum-keepers. Nature 438:156.

Isaac NJB, Turvey ST, Collen B, Waterman C, Baillie JEM. 2007. Mammals on the EDGE: conservation priorities based on threat and phylogeny. Plos One 2:e296.

IUCN (International Union for Conservation of Nature ) 2014. The IUCN red list of threatened species. Version 2014.3. Available from http://www.iucnredlist.org .

Jenkins M. 1992. Species extinction. Pages 192-233 in Groombridge B, editor. Global biodiversity: Status of the Earths' living resources. Chapman \& Hall, London.

Jono CMA, Pavoine S. 2012. Threat diversity will erode mammalian phylogenetic diversity in the near future. Plos One 7:e46235.

Kareiva P, Marvier M. 2012. What is conservation science? BioScience, 62:962-969.

Laity T et al. 2015. Phylodiversity to inform conservation policy: An Australian example. Science of the Total Environment 534:131-143.

Lawrence D, Fiegna F, Behrends V, Bundy JG, Phillimore AB, Bell T, Barraclough TG. 2012. Species interactions alter evolutionary responses to a novel environment. PLoS Biology 10:e1001330.

Lawson CR, Benni JJ, Thomas CD, Hodgson JA, Wilson RJ. 2014. Active management of protected areas enhances metapopulation expansion under climate change. Conservation Letters 7:111-118.

Lövbrand E, Beck S, Chilvers J, Forsyth T, Hedrén J, Hulme M, Lidskog R, Vasileiadou E. 2015. Who speaks for the future of Earth? How critical social science can extend the conversation on the Anthropocene. Global Environmental Change 32:211-218. 
Mace GM, Purvis A. 2008. Evolutionary biology and practical conservation: bridging a widening gap. Molecular Ecology 17:9-19.

Mace GM. 2014. Whose conservation. Science 345:1558- 1560.

Minteer BA, Collins JP. 2010. Move it or lose it? The ecological ethics of relocating species under climate change. Ecological Applications 20:1801-1804.

Mouillot D et al. 2014. Functionak over-redundancy and high functional vulnerability in global fish faunas on tropical. Proceedings of the National Academy of Sciences USA 111:137575-13762.

Nordhaus T, Shellenberger M. 2007. Break Through: From the Death of Environmentalism to the Politics of Possibility. Houghton Mifflin, New York.

Noss R, Nash R, Paquet P, Soulé M. 2013. Humanity's domination of nature is part of the problem: A response to Kareiva and Marvier. BioScience 63:241-242.

Palsson G et al. 2013. Reconceptualising the 'Anthropos' in the Anthropocene. Environmental Science and Policy 28:3-13.

Palumbi SR. 2001. The Evolution Explosion: How Humans Cause Rapid Evolutionary Change. W.W. Morton, New York.

Pauly D. 1995. Anecdotes and the shifting baseline syndrome of fisheries. Trends in Ecology and Evolution 10:430.

Pavoine S, Bonsall MB. 2011. Measuring biodiversity to explain community assembly: a unified approach. Biological Reviews 86:792-812.

Picketty T. 2014. Capital in the twenty-first century. Harvard University Press, Cambridge, Massachusetts.

Quental TB, Marshall CR. 2009. Extinction during evolutionary radiations: reconciling the fossil record with molecular phylogenies. Evolution 63:3158-3167. 
Ripple WJ et al. 2014. Status and ecological effects of the world's largest carnivores. Science 343:151-163.

Robert A, Thévenin C, Princé K, Sarrazin F, Clavel J. 2016. De-extinction and evolution. Functional Ecology DOI:10.1111/1365-2435.12723.

Robert A. 2009. Captive breeding genetics and reintroduction success. Biological Conservation 142:2915-2922.

Rojas M. 1992. The species problem and conservation: what are we protecting? Conservation Biology 6:170-178.

Sandler R. 2013. The ethics of reviving long extinct species. Conservation Biology 28:354360.

Sarkar S. 2012. Environmental Philosophy: From Theory to Practice. Wiley-Blackewell, Hoboken, New Jersey.

Sarrazin F, Lecomte J. 2016. Evolution in the Anthropocene. Science 351:922-923.

Schmitz OJ. 2016. The New Ecology: Rethinking a Science for the Anthropocene. Princeton University Press, Princeton, New Jersey.

Seddon PJ, Griffiths CJ, Soorae PS, Armstrong DP. 2014. Reversing defaunation: Restoring species in a changing world. Science 345:406-412.

Smith TB, Bruford MW, Wayne RK. 1993. The preservation of process: the missing element of conservation programs. Biodiversity Letters 1:164-167.

Soulé ME. 1985. What is conservation biology? BioScience 35:727-734.

Stockwell CA, Hendry AP, Kinnison MT. 2003. Contemporary evolution meets conservation biology. Trends in Ecology and Evolution 18:94-101.

Tallis H, Lubchenco J. 2014. Working together: a call for inclusive conservation. Nature 515:27-28. 
Thomas CD. 2011. Anthropocene park? no alternative. Trends in Ecology and Evolution 26:497-498.

Tidball KG. 2012. Urgent biophilia: human-nature interactions and biological attractions in disaster resilience. Ecology and Society 17:5.

Toledo D, Agudelo MS, Bently AL. 2012. The shifting of ecological restoration benchmarks and their social impacts: digging deeper into pleistocene re-wilding. Restoration Ecology 19:564-568.

Vucetich JA, Bruskotter JT, Nelson MP. 2015. Evaluating whether nature's intrinsic value is an axiom of or anathema to conservation. Conservation Biology 29:321-332.

Webb CO, Ackerly DD, McPeek MA, Donoghue MJ. 2002. Phylogenies and Community Ecology. Annual Review of Ecology, Evolution, and Systematics 33:475-505.

Willis KK, Birks HJB. 2006. What is natural? The need for a longterm perspective in biodiversity conservation. Science 314:1261-1265.

Winker K. 1996. The Crumbling Infrastructure of Biodiversity: The Avian Example. Conservation Biology 10:703-707.

Winter M, Devictor V, Schweiger O. 2013. Phylogenetic diversity and nature conservation: where are we? Trends in Ecology and Evolution 28:199-204. 